\title{
Early Morning QT Prolongation During Hypoglycemia: Only a Matter of Glucose?
}

\author{
Sara D'Imperio ${ }^{1+}$, Michelle M. Monasky ${ }^{1+}$, Emanuele Micaglio ${ }^{1}$, Gabriele Negro ${ }^{1}$ and \\ Carlo Pappone ${ }^{1,2 *}$ \\ ${ }^{1}$ Arrhythmology Department, IRCCS Policlinico San Donato, Milan, Italy, ${ }^{2}$ Vita-Salute San Raffaele University, Milan, Italy
}

Keywords: QT prolongation, hypoglycemia, Brugada syndrome, diabetes, sudden cardiac death, glucose, glucose - insulin

QT is the surface ECG equivalent of the time it takes for the ventricular myocardium to repolarize after its depolarization. The prolongation of the QT interval is a dangerous ECG abnormality that can be inherited or acquired and is a risk for sudden cardiovascular events due to its potential arrhythmogenicity. The prevalence of QT prolongation has been investigated in both type 1 and type 2 diabetes mellitus (DM) (1). It has been demonstrated that QT prolongation is a risk factor for

OPEN ACCESS

Edited by:

Marina Cerrone,

New York University, United States

Reviewed by:

Pier Leopoldo Capecchi,

University of Siena, Italy

David Auerbach,

Upstate Medical University,

United States

*Correspondence:

Carlo Pappone

carlo.pappone@af-ablation.org

tThese authors have contributed equally to this work

Specialty section:

This article was submitted to

Cardiac Rhythmology

a section of the journal

Frontiers in Cardiovascular Medicine

Received: 31 March 2021 Accepted: 19 April 2021 Published: 11 May 2021

Citation:

D'Imperio S, Monasky MM, Micaglio E, Negro G and Pappone C (2021) Early Morning QT Prolongation

During Hypoglycemia: Only a Matter of Glucose?

Front. Cardiovasc. Med. 8:688875.

doi: 10.3389/fcrm.2021.688875 sudden cardiac death in the presence of hypoglycemia (2), including when it is insulin-induced (3).

We read with great interest the retrospective study by Tsujimoto et al. reporting that in the early morning ( 4 a.m. -10 a.m.) severe hypoglycemia was associated with a significant incidence of abnormal QT prolongation in a cohort of 287 Japanese patients, regardless of whether the patients were diabetic or not (4). This study focused on the relationship between QT prolongation and severe hypoglycemia, which is a common and deleterious effect of diabetes and has been associated with adverse cardiovascular outcomes, such as fatal cardiac arrhythmic events $(5,6)$ and mortality (7). Indeed, several studies support that there is a strict correlation between hypoglycemia and arrhythmic events during bedtime in diabetic patients $(6,8-10)$, with a significant increase in prolonged QT interval (11-13). Of note, in the human species, the length of the QT interval has been shown to depend upon the circadian rhythm, which is controlled by the autonomous nervous system and was shown to have marked variability in patients with type 1 diabetes mellitus (14). We are aware that maturity onset diabetes of the young (MODY) is not a common cause of diabetes worldwide, although an excellent study by Yorifuji et al. (15) reported 103 mutations in MODY genes (39\%) in a cohort of 263 Japanese diabetic patients. Therefore, we suggest the analysis of at least the genes GCK, HNF1A, HNF1B, and HNF4A in the cohort presented by Tsujimoto and coworkers.

Lengthened QT interval is associated with ventricular arrhythmias and sudden cardiac death (16). It can be caused by genetic variations, mineral imbalance, or QT-prolonging medications $(17,18)$. Moreover, a higher incidence of QT prolongation has been described in metabolic syndrome (19), eating disorders, such as anorexia nervosa (20), and obesity (21). Therefore, it is very important to identify the underlying conditions of the patients that influence their QT interval and risk of mortality.

Multiple regulatory mechanisms are implicated in balancing the serum glucose concentration with the circadian rhythm. Therefore, when this balance is disrupted, hypoglycemia can occur. This condition usually occurs in diabetic patients due to the administration of hypoglycemic agents, such as insulin or sulfonylurea. However, hypoglycemia can develop due to several clinical complications, such as metabolic diseases (22), insulinoma (23), and non-islet tumors (24). Moreover, regardless of a patient's diet, hypoglycemia can also manifest due to an excess intake of alcohol, because it inhibits both hepatic gluconeogenesis and glycogenolysis (25-27). Autoimmunity is another important cause of both hypoglycemia and QT interval prolongation. 
Type 1 diabetes is characterized by the presence of many different antibodies (28). Those antibodies provoke autoimmune destruction of insulin-producing $\beta$ cells (29) and can be detected in the patients' plasma. Thus, it is very important to exclude the presence of such mechanisms in the studied cohort.

Of note, in the present article by Tsujimoto et al., we did not find any information regarding the clinical status of non-DM patients, in particular the prevalence of potentially QT prolonging conditions [hypokalemia, QT prolonging drugs, metabolic disorders others than diabetes, or inflammation (30)]. Therefore, it would be better to understand the etiology of the severe hypoglycemia, because it may be the cause or a contributing cause of the QT prolongation. This ECG abnormality happens spontaneously in the hereditary form, but can be triggered by drugs (https://www.crediblemeds.org), such as antiarrhythmics, antihistamines, antipsychotics, antibiotics (18), cancer treatments, and alcohol intake $(25,26)$. Furthermore, no genetic testing is presented about the most common long QT syndrome (LQTS) genes (KCNQ1, KCNH2, SCN5A, or possible modulating polymorphisms).

Moreover, we noticed that Tsujimoto et al. only took into consideration the QT interval and no other important electrocardiogram (ECG) information, such as ST-segment and $\mathrm{T}$ wave. Clinical similarities exist among patients with prolonged QT interval and Brugada syndrome (BrS), and the majority of these patients are asymptomatic, yet they can be at risk of sudden cardiac death (31-33).

BrS and LQTS are both life-threatening inherited arrhythmic disorders that usually manifest in the nighttime. LQTS type-3 and $\mathrm{BrS}$ also share the same SCN5A variant $(34,35)$, and several instances of an overlap syndrome have been described $(34,36)$. Therefore, the evaluation of the ST-segment could have been useful to unveil an overlap syndrome.

We understand why cardiopulmonary arrest patients were excluded from the study, however, it would have been useful to evaluate, if available, the ECGs of those patients, since they showed the worst phenotype. Therefore, it would have been interesting if those patients had prior clinical evaluations of their health conditions. Specifically, it would have been useful to know if they have ever had any symptoms like syncope, palpitations, seizures, or family history related to $\mathrm{BrS}$, and more importantly, whether the ST-segment from a standard 12-precordial lead ECG had ever been evaluated. Notably, the patients presented to a hospital in Japan, which has a relatively high incidence of BrS, ranging from 0.1 to $0.2 \%$ in the general population (37).

It is known that many cardiovascular outcomes vary in prevalence depending the time of the day. Indeed, the cardiac circadian rhythm is involved in different cardiac functions and it may contribute to HF and SCD (38). We noticed that in the study conducted by Tsujimoto et al., the QT prolongation was only assessed in patients with severe hypoglycemia. It would

\section{REFERENCES}

1. Kumar R, Fisher M, Macfarlane PW. Review: diabetes and the QT interval: time for debate. $B r \quad J$ Diabetes Vasc Dis. (2004) 4:146-50. doi: 10.1177/14746514040040030201 have been helpful to have QT prolongation records of the same patients or a matched cohort, during periods of nonhypoglycemia. Moreover, to better understand the relationship between QT prolongation and hypoglycemia events, it would also be important to know the QT baseline at different times of day in order to determine the effect of the circadian fluctuations on the QT interval. In fact, two types of circadian clocks exist: a central clock that acts on the heart by various neurohumoral factors, and a local clock in the heart that alters the expression of cardiac ion channels (39). At night, the QT interval (as well as the PR interval and QRS duration) is lengthened, indicating slower ventricular repolarization. A possible mechanism for this may include ion channel remodeling, including $\mathrm{Na}^{+}, \mathrm{Ca}^{2+}$, and $\mathrm{K}^{+}$channels, as well as connexins, as a result of circadian rhythm, as demonstrated in animal models (39). Therefore, in the study by Tsujimoto et al., it is not clear how it is possible to distinguish the role of hypoglycemia vs. the role of the time of day impacting the QT when the study included only data investigating hypoglycemia during early morning.

On another note, only patients with hypoglycemia were included in the study, but the relationship between blood glucose and QT prolongation was not discussed. A strict temporal relationship has been described between hypoglycemia and QT prolongation, stressing the proarrhythmic harm related to dynamic changes of heart repolarization (40). Thus, it would have been optimal to understand the duration of QT prolongation at different blood glucose concentrations. Indeed, this issue would have been better understood if several blood glucose values, including non-hypoglycemic readings, could have been included.

In conclusion, according to current literature, it is not possible to consider an abnormal QT prolongation during the early morning as just an expression of severe hypoglycemia. In fact, QT trait prolongation can be an expression of a concealed channelopathy (possibly overlap syndrome), a sign of non-alcoholic fatty liver disease, regardless of the presence of diabetes (41), or the onset of metabolic dysregulation, potentially associated with several different cardiomyopathies with preserved ejection fraction (HFpEF) (42).

\section{AUTHOR CONTRIBUTIONS}

SD'I and MM decided on the project, drafted the original version, and revised the manuscript. EM and GN provided expertise and revised the manuscript. CP provided resources and funding. All authors contributed to the article and approved the submitted version.

\section{FUNDING}

This study was partially supported by Ricerca Corrente funding from Italian Ministry of Health to IRCCS Policlinico San Donato.

2. Nordin C. The proarrhythmic effect of hypoglycemia: evidence for increased risk from ischemia and bradycardia. Acta Diabetol. (2014) 51:514. doi: 10.1007/s00592-013-0528-0

3. Kacheva S, Karges B, Göller K, Marx N, Mischke K, Karges W. QT prolongation caused by insulin-induced hypoglycaemia - an interventional 
study in 119 individuals. Diabetes Res Clin Pract. (2017) 123:16572. doi: 10.1016/j.diabres.2016.11.021

4. Tsujimoto T, Yamamoto-Honda R, Kajio H, Kishimoto M, Noto H, Hachiya $\mathrm{R}$, et al. High risk of abnormal QT prolongation in the early morning in diabetic and non-diabetic patients with severe hypoglycemia. Ann Med. (2015) 47:238-44. doi: 10.3109/07853890.2015.1017528

5. Clus S, Crețeanu G, Popa A. Nocturnal hypoglycemia in type 2 diabetes. Romanian J Diabetes Nutr Metab Dis. (2018) 25:99-103. doi: 10.2478/rjdnmd-2018-0011

6. Andersen A, Jørgensen PG, Knop FK, Vilsbøll T. Hypoglycaemia and cardiac arrhythmias in diabetes. Ther Adv Endocrinol Metab. (2020) 11:2042018820911803. doi: 10.1177/2042018820911803

7. Amiel SA, Aschner P, Childs B, Cryer PE, de Galan BE, Frier BM, et al. Hypoglycaemia, cardiovascular disease, and mortality in diabetes: epidemiology, pathogenesis, and management. Lancet Diabetes Endocrinol. (2019) 7:385-96. doi: 10.1016/S2213-8587(18)30315-2

8. Stahn A, Pistrosch F, Ganz X, Teige M, Koehler C, Bornstein S, et al. Relationship between hypoglycemic episodes and ventricular arrhythmias in patients with type 2 diabetes and cardiovascular diseases: silent hypoglycemias and silent arrhythmias. Diabetes Care. (2014) 37:51620. doi: $10.2337 / \mathrm{dc} 13-0600$

9. Reno CM, Daphna-Iken D, Chen YS, VanderWeele J, Jethi K, Fisher SJ. Severe hypoglycemia-induced lethal cardiac arrhythmias are mediated by sympathoadrenal activation. Diabetes. (2013) 62:3570-81. doi: 10.2337/db13-0216

10. Chow E, Bernjak A, Williams S, Fawdry RA, Hibbert S, Freeman J, et al. Risk of cardiac arrhythmias during hypoglycemia in patients with type 2 diabetes and cardiovascular risk. Diabetes. (2014) 63:1738-47. doi: 10.2337/db1 3-0468

11. Robinson RT, Harris ND, Ireland RH, Macdonald IA, Heller SR. Changes in cardiac repolarization during clinical episodes of nocturnal hypoglycaemia in adults with Type 1 diabetes. Diabetologia. (2004) 47:312-5. doi: 10.1007/s00125-003-1292-4

12. Marques JL, George E, Peacey SR, Harris ND, Macdonald IA, Cochrane $\mathrm{T}$, et al. Altered ventricular repolarization during hypoglycaemia in patients with diabetes. Diabet Med J Br Diabet Assoc. (1997) 14:64854. doi: 10.1002/(SICI)1096-9136(199708)14:8<648::AID-DIA418>3.0.CO;2-1

13. Ko S-H, Park Y-M, Yun J-S, Cha S-A, Choi E-K, Han K, et al. Severe hypoglycemia is a risk factor for atrial fibrillation in type 2 diabetes mellitus: Nationwide population-based cohort study. J Diabetes Complications. (2018) 32:157-63. doi: 10.1016/j.jdiacomp.2017.09.009

14. Kardelen F, Akçurin G, Ertu,g H, Akcurin S, Bircan I. Heart rate variability and circadian variations in type 1 diabetes mellitus. Pediatr Diabetes. (2006) 7:45-50. doi: 10.1111/j.1399-543X.2006. 00141.x

15. Yorifuji T, Higuchi S, Kawakita R, Hosokawa Y, Aoyama T, Murakami A, et al. Genetic basis of early-onset, maturity-onset diabetes of the young-like diabetes in Japan and features of patients without mutations in the major MODY genes: dominance of maternal inheritance. Pediatr Diabetes. (2018) 19:1164-72. doi: 10.1111/pedi.12714

16. Algra A, Tijssen JG, Roelandt JR, Pool J, Lubsen J. QTc prolongation measured by standard 12-lead electrocardiography is an independent risk factor for sudden death due to cardiac arrest. Circulation. (1991) 83:188894. doi: 10.1161/01.CIR.83.6.1888

17. Castiglione A, Odening K. QT-Zeit - was fange ich eigentlich damit an? Dtsch Med Wochenschr. (2020) 145:536-42. doi: 10.1055/a-096 9-6312

18. Nachimuthu S, Assar MD, Schussler JM. Drug-induced QT interval prolongation: mechanisms and clinical management. Ther Adv Drug Saf. (2012) 3:241-53. doi: 10.1177/2042098612454283

19. Guo X, Li Z, Guo L, Yu S, Yang H, Zheng L, et al. Effects of metabolically healthy and unhealthy obesity on prolongation of corrected QT interval. Am J Cardiol. (2017) 119:1199-204. doi: 10.1016/j.amjcard.2016. 12.033

20. Takimoto Y, Yoshiuchi K, Kumano H, Yamanaka G, Sasaki T, Suematsu H, et al. QT interval and QT dispersion in eating disorders. Psychother Psychosom. (2004) 73:324-8. doi: 10.1159/000078850
21. Kumar T, Jha K, Sharan A, Sakshi P, Kumar S, Kumari A. Study of the effect of obesity on QT-interval among adults. J Fam Med Prim Care. (2019) 8:1626-9. doi: 10.4103/jfmpc.jfmpc_168_19

22. Douillard C, Mention K, Dobbelaere D, Wemeau J-L, Saudubray JM, Vantyghem M-C. Hypoglycaemia related to inherited metabolic diseases in adults. Orphanet J Rare Dis. (2012) 7:26. doi: 10.1186/1750-1 $172-7-26$

23. Kandaswamy L, Raghavan R, Pappachan JM. Spontaneous hypoglycemia: diagnostic evaluation and management. Endocrine. (2016) 53:47-57. doi: 10.1007/s12020-016-0902-0

24. Bodnar TW, Acevedo MJ, Pietropaolo M. Management of non-islet-cell tumor hypoglycemia: a clinical review. J Clin Endocrinol Metab. (2014) 99:71322. doi: 10.1210/jc.2013-3382

25. van de Wiel A. Diabetes mellitus and alcohol. Diabetes Metab Res Rev. (2004) 20:263-7. doi: $10.1002 / \mathrm{dmrr} .492$

26. Oba-Yamamoto C, Takeuchi J, Nakamura A, Takikawa R, Ozaki A, Nomoto $\mathrm{H}$, et al. Combination of alcohol and glucose consumption as a risk to induce reactive hypoglycemia. J Diabetes Investig. (2021) 12:6517. doi: 10.1111/jdi.13375

27. Spoke C, Malaeb S. A case of hypoglycemia associated with the ketogenic diet and alcohol use. J Endocr Soc. (2020) 4:bvaa045. doi: 10.1210/jendso/ bvaa045

28. Kahaly GJ, Hansen MP. Type 1 diabetes associated autoimmunity. Autoimmun Rev. (2016) 15:644-8. doi: 10.1016/j.autrev.2016.02.017

29. Bluestone JA, Herold K, Eisenbarth G. Genetics, pathogenesis and clinical interventions in type 1 diabetes. Nature. (2010) 464:1293300. doi: 10.1038 /nature 08933

30. Lazzerini PE, Acampa M, Laghi-Pasini F, Bertolozzi I, Finizola F, Vanni F, et al. Cardiac arrest risk during acute infections: systemic inflammation directly prolongs QTc interval via cytokine-mediated effects on potassium channel expression. Circ Arrhythm Electrophysiol. (2020) 13:e008627. doi: 10.1161/CIRCEP.120.008627

31. Obeyesekere MN, Antzelevitch C, Krahn AD. Management of ventricular arrhythmias in suspected channelopathies. Circ Arrhythm Electrophysiol. (2015) 8:221-31. doi: 10.1161/CIRCEP.114. 002321

32. Haïssaguerre M, Extramiana F, Hocini M, Cauchemez B, Jaïs P, Cabrera JA, et al. Mapping and ablation of ventricular fibrillation associated with long-QT and brugada syndromes. Circulation. (2003) 108:9258. doi: 10.1161/01.CIR.0000088781.99943.95

33. Romero D, Behar N, Mabo P, Hernandez AI. Differences in brugada syndrome patients through ventricular repolarization analysis during sleep. In: $201941 s t$ Annual International Conference of the IEEE Engineering in Medicine Biology Society (EMBC). Presented at the 2019 41st Annual International Conference of the IEEE Engineering in Medicine \& Biology Society (EMBC). Berlin: IEEE (2019). p. 5638-41.

34. Hasebe H, Yokoya T, Murakoshi N, Kurebayashi N. Pilsicainide administration unmasks a phenotype of Brugada syndrome in a patient with overlap syndrome due to the E1784K SCN5A mutation. Intern Med Tokyo Jpn. (2020) 59:83-7. doi: 10.2169/internalmedicine. 3430-19

35. Sandhu A, Borne RT, Mam C, Bunch TJ, Aleong RG. Double jeopardy: long QT3 and Brugada syndromes. Clin Case Rep. (2017) 5:13159. doi: $10.1002 / \mathrm{ccr} 3.1064$

36. Bezzina C, Veldkamp MW, van Den Berg MP, Postma AV, Rook MB, Viersma JW, et al. A single $\mathrm{Na}(+)$ channel mutation causing both long-QT and Brugada syndromes. Circ Res. (1999) 85:1206-13. doi: 10.1161/01.RES.85.12.1206

37. Hiraoka M. Brugada syndrome in Japan. Circ J. (2007) 71(Suppl. A):A618. doi: $10.1253 /$ circj.71.A61

38. Bernardi J, Aromolaran KA, Zhu H, Aromolaran AS. Circadian mechanisms: cardiac ion channel remodeling and arrhythmias. Front Physiol. (2020) 11:611860. doi: 10.3389/fphys.2020.611860

39. Black N, D'Souza A, Wang Y, Piggins H, Dobrzynski H, Morris G, et al. Circadian rhythm of cardiac electrophysiology, arrhythmogenesis, and the underlying mechanisms. Heart Rhythm. (2019) 16:298-307. doi: 10.1016/j.hrthm.2018.08.026 
40. Lee AS, Brooks BA, Simmons L, Kilborn MJ, Wong J, Twigg SM, et al. Hypoglycaemia and QT interval prolongation: detection by simultaneous Holter and continuous glucose monitoring. Diabetes Res Clin Pract. (2016) 113:211-4. doi: 10.1016/j.diabres.2016.01.005

41. Hung C-S, Tseng P-H, Tu C-H, Chen C-C, Liao W-C, Lee Y$\mathrm{C}$, et al. Nonalcoholic fatty liver disease is associated with QT prolongation in the general population. J Am Heart Assoc. (2015) 4:e001820. doi: 10.1161/JAHA.115.001820

42. Tune JD, Goodwill AG, Sassoon DJ, Mather KJ. Cardiovascular consequences of metabolic syndrome. Transl Res J Lab Clin Med. (2017) 183:5770. doi: 10.1016/j.trsl.2017.01.001
Conflict of Interest: The authors declare that the research was conducted in the absence of any commercial or financial relationships that could be construed as a potential conflict of interest.

Copyright (C) 2021 D'Imperio, Monasky, Micaglio, Negro and Pappone. This is an open-access article distributed under the terms of the Creative Commons Attribution License (CC BY). The use, distribution or reproduction in other forums is permitted, provided the original author(s) and the copyright owner(s) are credited and that the original publication in this journal is cited, in accordance with accepted academic practice. No use, distribution or reproduction is permitted which does not comply with these terms. 